\title{
The Impact of Restaurant Table Characteristics on Meal Duration and Spending
}

by SHERYL E. KIMES and STEPHANI K. A. ROBSON

Restaurateurs seeking to maximize revenues should look carefully at how long their tables are occupied and at how much the average diner spends. This study examines two aspects of the restaurant environment-table type and table location-to determine whether the placement or configuration of a dining table (in particular, whether it has an architectural anchor) has measurable effects on duration and average check, which were combined to show average spending per minute (SPM). An analysis of more than fourteen hundred meal transactions at a 210-seat, casual Mexican-style restaurant found that the SPM for parties at booths was slightly higher than average, while the SPM for diners at banquette tables was below the average. Ironically, tables in poor locations in the dining room generated SPM values higher than supposedly good tables. These findings suggest that restaurant designers reexamine the use of banquettes and not be overly concerned about "bad" tables.

Keywords: restaurant design; revenue management; floor planning

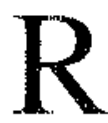
estaurant revenue management examines the most effective ways of balancing restaurant demand and supply to maximize revenue without compromising customer satisfaction.' Important tools in the revenue management arsenal have been 
those that account for the amount of time and money spent at table and the rate at which money is spent. These three meatsures-duration, average check, and revenue per available seat-hour (RevPASH) are of key interest to any operator who seeks to maximize the revenue potential of a restaurant. ${ }^{2}$

A lurther element that bears examination when detemining revenue potential is capacity in terms of the number and configuration of tables. A typical restaurant ofters a mix of table sizes and types, including lreestanding tables for different party sizes, fixed-seating booths, flexible banquettes, and perhaps bar seating at high-top tables or at the bar itself. The selected table mix is typically a function of the market scgment that the restaurant hopes to atract, the environment that the restaurant designer and management hope to create, and the architectural limitations of the space. While the restaurant industry readily acknowledges that guests seem to prefer some table types over others-lor instance, the romantic table for two in the window, the cozy booth in the corner-no formal rescarch hats examined whether table characteristics such as configuration and location have any real effect on how long guests occupy a table or how much they spond.

This article is a first foray into exploring the relationship of restaurant table characteristics with spending and duration. By understanding the ways that table type and location affect the amount of lime and money spent, restaurant operators and designers can develop lacilities that will assist in revenue maximization.

In keeping with restaurant industry practice, this study defines spending as overall average check for each party. Duration is an approximation of the amount of time a given table is occupied. determined by the opening and closing times on the check, as recorded by the restaturant's POS system. This record may not be a completely accurate measure of the exact number of minutes spent at table. but it is a reasonable estimate of the time al table is accupied.

While average check and duration are measures that most restaurateurs understand and may use as part of a revenue mamagement program, it is the combination of these two measures that is of most interest. A long duration with a low average check ties up seating inventory but does not generate a great deal of revenue for an operator. A high average check and a long duration is acceptable but may not represent the optimal revenue-generating capacity of the restaurant. The ideal, needless to say, is a high average check and a relatively short duration, which makes good use of scating inventory and generates the greatest revenucs. The average check per person per minute, which we will reter to as spending per minute (SPM), is our measure of the rate al which a seal generates revenue. We lelt that combining average check and duration into a single measure best allowed us to analyze the effectiveness of a given table location in light of the operator's goals to keep duration down and spending up.

We begin by brielly reviewing research findings in environmental psychology and restaurant revenue management that relate to seating and behavior, then we describe the restaurant under study, and we explain the analysis that we performed on four weeks of $P O S$ data. We conclude with a discussion of how our findings might affect the planning and operation of similar restausants and explore areas in which lurther research on the relationship between restaurant design and guest behavior might be valuable to restaurant planners and managers. 


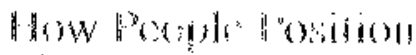

"Whemson:

Restaurateurs implicitly know that table characteristics affect restaurant patrons' behavior, even if the reasons are not always clear. Research examining personal territory helps us to understand some of that behavior. The social science literature indicates that where we position ourselves relative to others and relative to prominent architectural features can have a significant effect on our emotional comfort, our willingness to aftiliate with others, and our desire to stay in a given setting.

Behavior in public settings is related to an inherent need to establish and maintain personal territory. Having sufficient personal territory allows us to regulate our contact with others, thus ensuring both privacy and security. ${ }^{3}$ The need for privacy and related territorial behavior vary as conditions and circumstances change. A substantial body of research has examined privacy-regulating behavior in public settings, and much is known about what has been termed "situational territoriality," or how people define and defend their personal space in settings that they occupy only temporarily. ${ }^{+}$

For settings that are occupied for a short time, such ats a seat in a restaurant or bar. individuals and groups often choose architectural features such as walls or columns to help define their personal territory and regulate privacy. ${ }^{5}$ Once a group's territory is defined, the positioning of individuals within that group also affects behavior. Some seating configurations are more conducive to pleasant conversation than others. Seats at right angles to one another appear to encourage interaction, for instance, as opposed to seats directly facing a companion. "Studies of group interaction, though, show that group members who face one another directly have shorter pauses in conversation, resulting in more positive assessments of the experience."

Experimental and observational research into seating and behavior has been performed in a wide range of settings, but perhaps no environment has received as much attention as the classroom, where seat location has been shown to be related to participation rates, grades, and student personality. ${ }^{.}$Other researchers have studied seat selection in public spaces, such as airport lounges and taxis. and found that seating preference is a function of a person's gender, age, and group size." However, none of these studies examined duration of use or spending.

The retail environment has been studied extensively. While customers rarely sit in stores, the way a store is designed has a significant effect on customer-approach behavior, defined as the desire to enter, explore, affiliate with others, or purchase."" For example, in environments perceived as pleasant, shoppers spend both more time and more money."

Little research has been published examining patrons' behavior in restaurant settings. Sommer and Steele looked at the interaction of group size and duration of use in coffee shops and traditional restaurants, noting that in both settings, groups of diners occupied their tables for longer than patrons dining alone." However, those researchers did not specify the size of group that they studied or examine spending behavior or food consumption. Several other studies have examined food consumption in relation to group size in institutional food-service settings and also in bars. while another study found a relationship between the music played in a restaurant and customers' spending but did not examine duration." A review of design and operational techniques that may reduce duration in restaurants indicated that certain strategies may contrib- 
ute to shorter duration in restaurants, such as increasing stimulation through music, lighting, and interior décor while reducing opportunities for privacy regulation. ${ }^{1+}$ The only study we could identify that examined both spending and duration in a restaurant setting involved the music being played. That study found that faster music tempos reduced both duration and spending."

Even fewer studies have been performed on restaurant table configurations and locations. Based on that slender literature and a related study, we note an interaction between the character of the dining experience and the choice of dining seat. ${ }^{16}$ The study found that in dining situations that might be perceived as stressful, college students were more likely to select tables that offered greater privacy regulation-typically "anchored" against a wall. window, or other architectural featurethan they were a table that was exposed or "unanchored." For less stressful dining experiences, students preferred tables with a high perceived value-typically, by the window (with an exterior view). Although these findings were preliminary, it appears that anchored tables are preferred over unanchored tables regardless of the occasion or the cultural attiliation of the diner. The study did not examine whether a preference for a certain type of table translated into longer duration of higher spending. but it might be surmised that diners sitting at a prelerred table may exhibit stronger approach behavior.

Models of restautant table mix have been put forward by Kimes and Thompson indicating that the optimal mix of tables for a given restaurant can result in increased revenues. ${ }^{17}$ Thompson further explored restaurant table combinability, using computer models rather than an actual behavioral setting. ${ }^{18}$ While this work may prove useful in determining an appropriate mix of tables for a given restaurant, it stops shot of being able to suggest guidelines for positioning, configuration, and styles of the recommended table mix.

What becomes clear is that while the related literature suggests the possibility of an interaction between restaurant table characteristics and guests" bchavior, we could identify no published research that determines the presence or extent of this relationship. The study described here sought to establish the nature and extent of any connection to provide restaurant professionals with a solid foundation for determining the optimal table layout.

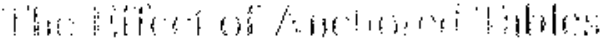

In this study, we examined whether restaurant table type and location affected duration, average check per person, and average SPM. We wanted to test the research that suggested that anchored tables might result in more time spent in the setting and higher spending. "Furthermore, we wanted to lest the finding that tables that position users in a face-to-face conliguration may lead to a longer stay and a larger average check than tables that place guests sicle by side.

In particular, we wanted to determine whether being seated at different types of anchored tables affected duration and average check. We divided anchored tables into the following subgroups: booths (tables with permanently fixed seating and solid architectural dividers on three sides of the table), banquettes (tables located along a permanently fixed bench with companions seated in chairs directly across the table from the diners seated on the bench), window tables (next to interior or exterior windows), and tables next to interior walls. We believed that the more privacy regulation a specitic table type offered, the higher the duration and aver- 
age check would be (and, therefore, the SPM). Thus, we hypothesized that booth seating might result in the longest duration and highest check average, given that a typical booth configuration supports privacy regulation on three sides.

In addition, we were curious whether "bad" table locations-for example, tables next to the kitchen or in high traftic areas-resulted in shorter duration or a lower average check than tables that were in less exposed locations.

\section{Problem Selting: Chevys Freshmex Restaurant}

To test our hypotheses, we collected data from a 210 -seat Chevys Freshmex Restaurant in suburban Phoenix. "*t Located in a busy shopping mall, the restaurant is part of a large chain of midprice Mexican restaurants, targeting young adults and families by offering an energetic atmosphere: quality food; reasonable prices; and friendly, informal service. This particular Chevys offered 31 twotops, 32 four-tops, and 4 five-tops. The restaurant also had an additional 50 to 60 seats in the bar areas and a further 45 to 50 seats on a seasonal outdoor patio. The restaurant's mall location resulted in a design with windows on both the outside of the space and on the inside separating the restaurant from the interior of the mall and from patio seating.

Chevys provided us with a dining room seating plan (Exhibit 1) for the restaurant showing table numbers, types, sizes, and locations and furnished four weeks of point-of-sale data, which indicated the table number, party size, spending. and the opening and closing times for each check. Inconsistencies in the bar and patio seating plans made it difficult to determine the seating capacity of some tables, so we eliminated those tables from our analysis.
Our study focused only on the restallrant's busy times (that is. Friday from 5:00 to $9: 00$ p.m. Saturday from noon to $2: 00$ p.m. and 6:00 to 9:00 p.m., and Sunday from 1:00 to 2:00 p.m.). During slow periods, staffing and service were inconsistent, making for erratic data. To control for the complicating factor of tables that might have been combined to accommodate large parties, we eliminated party sizes greater than three seated at two-tops and greater than six seated at four- and five-tops. In the end our data comprised 1,413 transactions. The mean dining duration, average check per person, and average SPM were calculated for each table type.

So-called bad tables might not be a bad thing for a restaurant, when one looks at customers' spending rates.

There were fifty-one anchored tables and sixteen unanchored tables. Anchored tables comprised nineteen tables against half-wall partitions, nine next to interior windows, ten next to exterior windows, four booths, and nine banquette tables (see Exhibit 2).

Freestanding tables for four were classified as seating patrons either in a sideby-side configuration or in a diagonal configuration. Side-by-side configuration consists of a rectangular table with two pairs of diners seated face to face directly opposite cach other; diagonal configuration consists of a square table with one diner on each side of the table (see Exhibit 3).

We also wanted to examine whether duration and spending were affected by whether a particular table was in a "bad" 
Exhibit 1:

Schematic Floor Plan

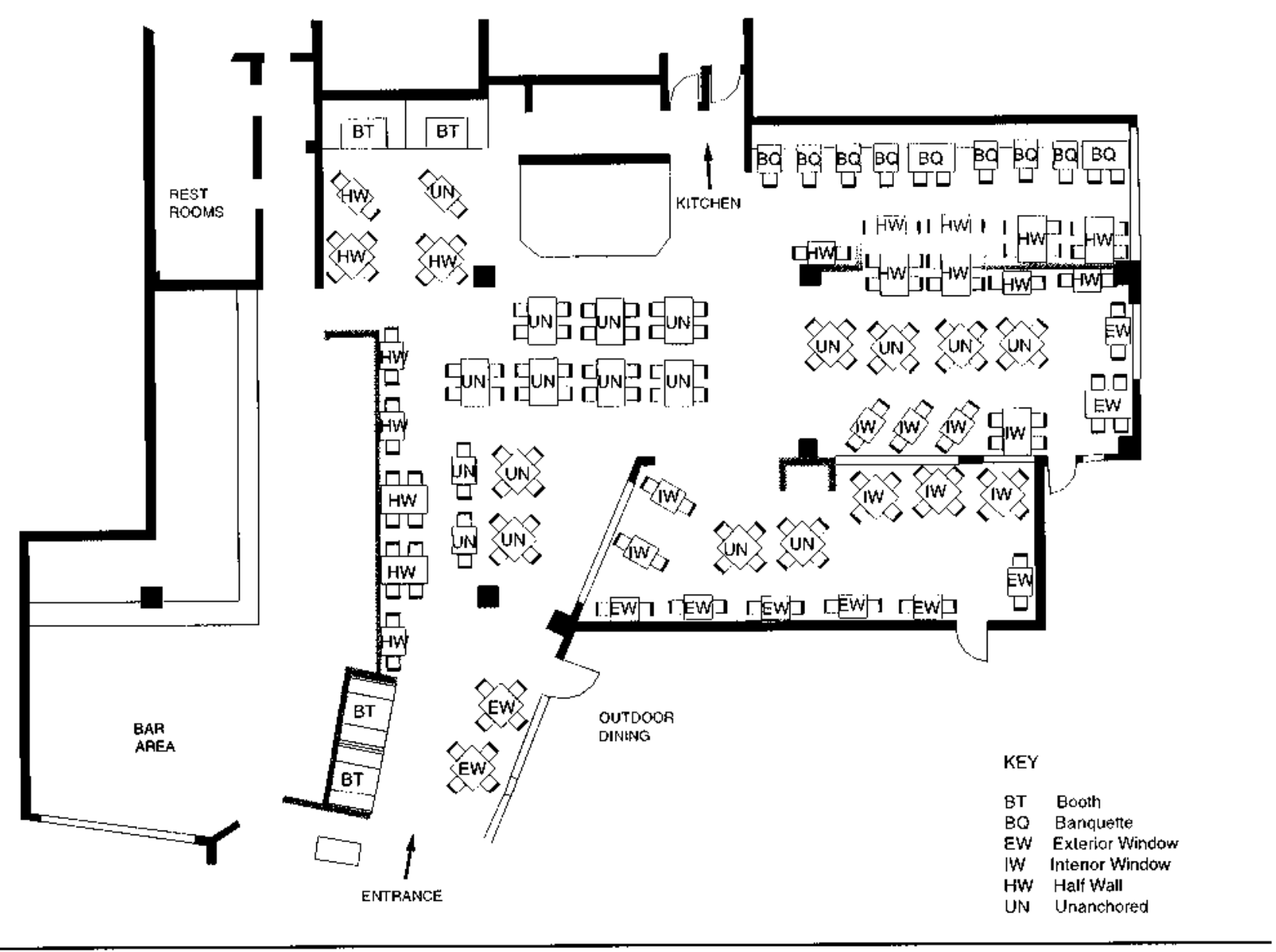

or undesirable location. Bad tables were defined as those next to the kitchen door, or tables for two that were sandwiched between larger tables that had high traffic and noise levels, or poor opportunities for privacy regulation. We classified seven tables as bad.

To test the interaction of table attributes with spending rates, we first developed descriptive statistics for our three depend- ent variables (Exhibit 4) and correlations between them (Exhibit 5). We then developed regression models (one for average SPM, one for average check per person, and one for average dining duration) for each of the four cases and controlled for party size and table size (Exhibits 6, 7, and $8)$. The average SPM was $\$ 0.29$ with a standard deviation of $\$ 0.12$. Customers in large parties had a lower SPM $(r=-.40)$ than did those dining in small parties. 
Exhibit 2:

Categorization of Restaurant Tables

\begin{tabular}{|c|c|c|c|c|c|c|c|}
\hline & \multicolumn{5}{|c|}{ Anchored } & \multirow[b]{2}{*}{$\begin{array}{c}\text { Un- } \\
\text { anchored }\end{array}$} & \multirow[b]{2}{*}{ Total } \\
\hline & $\begin{array}{l}\text { Half- } \\
\text { Wall }\end{array}$ & $\begin{array}{l}\text { Interior } \\
\text { Window }\end{array}$ & $\begin{array}{l}\text { Exterior } \\
\text { Window }\end{array}$ & Booth & Banquette & & \\
\hline Two-tops & 9 & 5 & 7 & & 7 & 3 & 31 \\
\hline Four-tops & 10 & 4 & 3 & & 2 & 13 & 32 \\
\hline Five-tops & & & & 4 & & & 4 \\
\hline Total & 19 & 9 & 10 & 4 & 9 & 16 & 67 \\
\hline
\end{tabular}

\section{Exhibit 3:}

Variations in Four-Top Seating Configuration
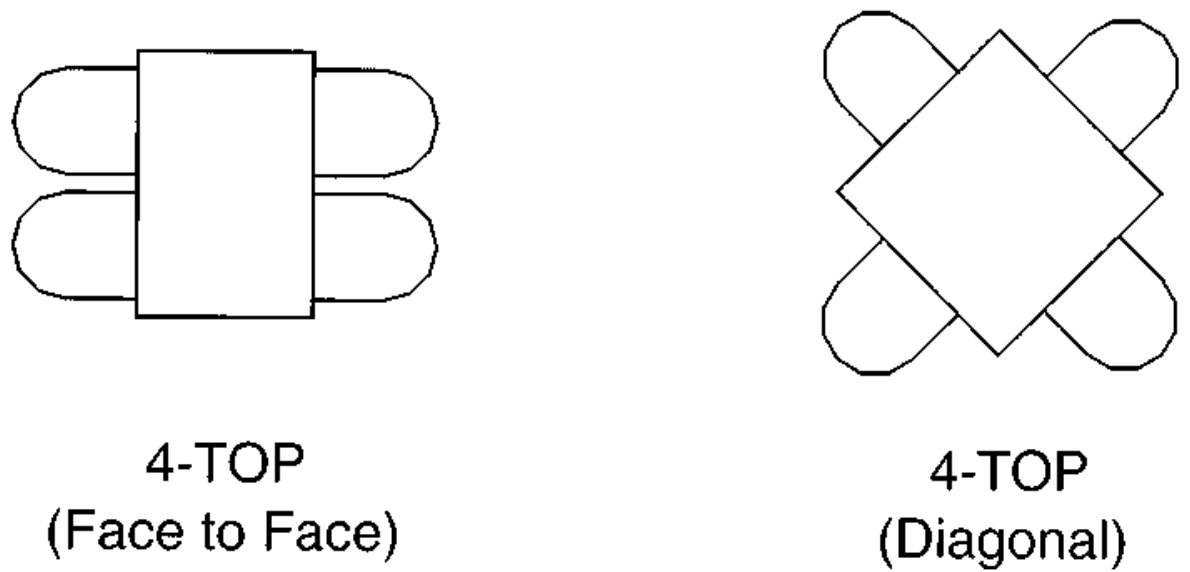

4-TOP

(Diagonal)

\section{Some Anthors lo Not illole}

Parties at anchored tables generally did not have significantly different SPM rates than did those at unanchored tables (anchored $=\$ 0.29$, unanchored $=\$ 0.29$ ). Party size and table size, however, were significantly related to SPM. Also, whether a table was good or bad had an effect, as we explain here. Although anchored tables as a group were not statistically different from other tables, the type of anchor made a difference $(p<.01)$. Customers seated at banquettes had a signitjcantly lower SPM (banquettes $=\$ 0.25$, all tables $=\$ 0.29$ ). Table configuration did not significantly affect SPM (diagonal = $\$ 0.28$, side by side $=\$ 0.27$ ). Interestingly, customers seated at bad tables had a 
Exhibit 4:

Descriptive Statistics

\begin{tabular}{|c|c|c|c|c|c|c|c|}
\hline & $\begin{array}{c}\text { Number } \\
\text { of } \\
\text { Observations }\end{array}$ & Minutes & $\begin{array}{c}\text { Standard } \\
\text { Deviation } \\
\text { of } \\
\text { Minutes }\end{array}$ & $\begin{array}{l}\text { Average } \\
\text { Check } \\
\text { per } \\
\text { Person }\end{array}$ & $\begin{array}{c}\text { Standard } \\
\text { Deviation } \\
\text { of } \\
\text { Average } \\
\text { Check per } \\
\text { Person }\end{array}$ & $\begin{array}{l}\text { Average } \\
\text { Spending } \\
\text { per } \\
\text { Minute }\end{array}$ & $\begin{array}{c}\text { Standard } \\
\text { Deviation } \\
\text { of } \\
\text { Average } \\
\text { Spending } \\
\text { per } \\
\text { Minute }\end{array}$ \\
\hline \multicolumn{8}{|l|}{ Anchor type } \\
\hline Banquette & 69 & 51.1 & 17.5 & $\$ 11.74$ & $\$ 3.68$ & $\$ 0.25$ & $\$ 0.09$ \\
\hline Booth & 122 & 48.6 & 19.2 & $\$ 14.21$ & $\$ 6.12$ & $\$ 0.31$ & $\$ 0.14$ \\
\hline Window & 245 & 47.1 & 16.0 & $\$ 12.36$ & $\$ 4.87$ & $\$ 0.28$ & $\$ 0.12$ \\
\hline Half-wall & 350 & 46.1 & 17.5 & $\$ 12.96$ & $\$ 4.77$ & $\$ 0.30$ & $\$ 0.11$ \\
\hline Interior window & 182 & 44.4 & 15.8 & $\$ 11.71$ & $\$ 4.31$ & $\$ 0.28$ & $\$ 0.12$ \\
\hline Anchored & 968 & 46.8 & 16.9 & $\$ 12.58$ & $\$ 4.89$ & $\$ 0.29$ & $\$ 0.12$ \\
\hline Unanchored & 377 & 46.5 & 17.8 & $\$ 12.51$ & $\$ 5.81$ & $\$ 0.29$ & $\$ 0.13$ \\
\hline \multicolumn{8}{|l|}{ Configuration } \\
\hline Diagonal & 347 & 47.4 & 16.1 & $\$ 12.65$ & $\$ 5.75$ & $\$ 0.28$ & $\$ 0.13$ \\
\hline Side by side & 327 & 47.4 & 17.9 & $\$ 12.10$ & $\$ 5.29$ & $\$ 0.27$ & $\$ 0.12$ \\
\hline \multicolumn{8}{|l|}{ Desirability } \\
\hline Good & 1,190 & 47.4 & 17.5 & $\$ 12.39$ & $\$ 5.00$ & $\$ 0.31$ & $\$ 0.12$ \\
\hline Bad & 155 & 41.7 & 13.1 & $\$ 12.59$ & $\$ 5.19$ & $\$ 0.28$ & $\$ 0.13$ \\
\hline \multicolumn{8}{|l|}{ Party size } \\
\hline 1 & 56 & 46.9 & 22.8 & $\$ 19.97$ & $\$ 10.28$ & $\$ 0.48$ & $\$ 0.22$ \\
\hline 2 & 785 & 44.6 & 14.4 & $\$ 13.15$ & $\$ 4.80$ & $\$ 0.31$ & $\$ 0.12$ \\
\hline 3 & 234 & 48.8 & 18.8 & $\$ 11.40$ & $\$ 3.96$ & $\$ 0.25$ & $\$ 0.09$ \\
\hline 4 & 196 & 51.2 & 19.5 & $\$ 10.60$ & $\$ 3.60$ & $\$ 0.22$ & $\$ 0.07$ \\
\hline 5 & 51 & 50.5 & 26.9 & $\$ 9.34$ & $\$ 3.26$ & $\$ 0.20$ & $\$ 0.08$ \\
\hline 6 & 23 & 51.3 & 10.3 & $\$ 10.10$ & $\$ 3.05$ & $\$ 0.20$ & $\$ 0.07$ \\
\hline \multicolumn{8}{|l|}{ Table size } \\
\hline 2 & 566 & 45.1 & 16.7 & $\$ 12.45$ & $\$ 4.49$ & $\$ 0.29$ & $\$ 0.11$ \\
\hline 4 & 658 & 47.8 & 17.1 & $\$ 12.36$ & $\$ 5.47$ & $\$ 0.28$ & $\$ 0.13$ \\
\hline 5 & 122 & 48.6 & 19.2 & $\$ 14.21$ & $\$ 6.12$ & $\$ 0.31$ & $\$ 0.14$ \\
\hline Total & 1,345 & 46.7 & 17.2 & $\$ 12.56$ & $\$ 5.17$ & $\$ 0.29$ & $\$ 0.12$ \\
\hline
\end{tabular}

higher SPM than those seated at good tables $(p<.01)($ bad $=\$ 0.31$, good $=$ $\$ 0.28)$.

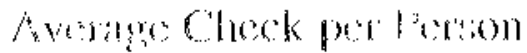

Average check per person may be interpreted in part als an indication of how comfortable a client feels at a table. Theoretically, customers seated at tables that offer more security should have a higher average check. The average check was $\$ 12.56$ with a standard deviation of $\$ 5.17$. Average check varied significantly by party size, with smaller parties tending to have a higher average check $(r=-.31)$.

Anchored. Once again, though, anchoring by itself had no statistical effect on 
Exhibit 5:

Correlation Analysis

\begin{tabular}{lccccc}
\hline & $\begin{array}{c}\text { Average } \\
\text { Check }\end{array}$ & Minutes & $\begin{array}{c}\text { Table } \\
\text { Size }\end{array}$ & $\begin{array}{c}\text { Party } \\
\text { Size }\end{array}$ & $\begin{array}{c}\text { Spending } \\
\text { per Minute }\end{array}$ \\
\hline Average check & 1.000 & & & & \\
Minutes & .251 & 1.000 & & & \\
Table size & .045 & .083 & 1.000 & & \\
Party size & -.306 & .137 & .379 & 1.000 & \\
Spending per minute & .689 & -.397 & -.031 & -.400 & 1.000 \\
\hline
\end{tabular}

Exhibit 6:

Average Spending per Person per Minute: Regression Results

\begin{tabular}{|c|c|c|c|}
\hline \multicolumn{2}{|c|}{ Anchored Tables } & \multicolumn{2}{|c|}{ Table Configuration } \\
\hline Variable & Coefficient & Variable & Coefficient \\
\hline Constant & $0.42 *$ & Constant & $0.41 *$ \\
\hline Anchored? & -0.01 & Diagonal & -0.01 \\
\hline Party size & $-0.05^{*}$ & Side by side & -0.01 \\
\hline Table size & $0.03^{*}$ & Party size & $-0.05^{*}$ \\
\hline \multirow[t]{2}{*}{$R$-squared } & $17.30 \%$ & Table size & $0.04^{*}$ \\
\hline & & $R$-squared & $17.10 \%$ \\
\hline \multicolumn{2}{|c|}{ Type of Anchor } & \multicolumn{2}{|c|}{ Table Quality } \\
\hline Variable & Coefficient & Variable & Coefficient \\
\hline Constant & $0.42^{*}$ & Constant & $0.40 *$ \\
\hline Banquette & $-0.04 *$ & Bad & $0.02^{*}$ \\
\hline Booth & 0.02 & Party size & $-0.05^{*}$ \\
\hline Half-wall & $-0.02^{*}$ & Table size & $0.04 *$ \\
\hline Interior window & $-0.02^{*}$ & $R$-squared & $17.40 \%$ \\
\hline Window & -0.01 & & \\
\hline Party size & $-0.05^{*}$ & & \\
\hline Table size & $0.02^{*}$ & & \\
\hline$R$-squared & $18.10 \%$ & & \\
\hline
\end{tabular}

*Significiant at the .05 level.

spending. The average check for customers seated at anchored tables was not significantly different from the average check for those seated at unanchored tables (anchored $=\$ 12.58$, unanchored $=$ $\$ 12.51)$.
Type of anchor: Again, the rype of anchor was related to average check $(p<$ .01). In particular, customers seated at booths spent significantly more per person than those seated at other table types (booths $=\$ 14.21$, all tables $=\$ 12.56$ ). 
Exhibit 7:

Average Check per Person: Regression Results

\begin{tabular}{|c|c|c|c|}
\hline \multicolumn{2}{|c|}{ Anchored Tables } & \multicolumn{2}{|c|}{ Table Configuration } \\
\hline Variable & Coefficient & Variable & Coefficient \\
\hline Constant & $16.49^{*}$ & Constant & $16.46^{*}$ \\
\hline Anchored? & -0.04 & Diagonal & $-0.85^{*}$ \\
\hline Party size & $-1.88^{*}$ & Side by side & $-0.98^{*}$ \\
\hline Table size & $1.75^{*}$ & Party size & $-1.86^{*}$ \\
\hline \multirow[t]{2}{*}{$R$-squared } & $11.50 \%$ & Table size & $2.44^{*}$ \\
\hline & & R-squared & $11.80 \%$ \\
\hline \multicolumn{2}{|c|}{ Type of Anchor } & \multicolumn{2}{|c|}{ Table Quality } \\
\hline Variable & Coefficient & Variable & Coefficient \\
\hline Constant & $16.81 *$ & Constant & $16.52^{*}$ \\
\hline Banquette & -0.50 & Bad & -0.22 \\
\hline Booth & $1.53^{*}$ & Party size & $-1.88^{*}$ \\
\hline Half-wall & -0.34 & Table size & $1.70^{*}$ \\
\hline Interior window & $-1.15^{*}$ & $R$-squared & $11.60 \%$ \\
\hline Window & 0.06 & & \\
\hline Party size & $-1.88^{*}$ & & \\
\hline Table size & $1.34^{*}$ & & \\
\hline$R$-squared & $12.70 \%$ & & \\
\hline
\end{tabular}

*Signalisant at the 05 level.

Also, customers seated at tables located next to interior windows had a lower average check (interior windows $=\$ 11.71$, all tables $=\$ 12.56$ ). Customers seated at other anchor types did not have a significantly different average check per person.

Table configuration and quality. Table configuration was not significantly related to average check per person (diagonal $=$ $\$ 12.65$, side by side $=\$ 12.10$, all tables $=$ $\$ 12.56)$. Table quality also was not significantly related to average check per person (bad $=\$ 12.59, \operatorname{good}=\$ 12.39)$.

\section{Nhal Duration}

Like average check per person, meal duration can be partly attributed to how comfortable customers are at a table. The- oretically, customers seated at tables that offer more porential for privacy regulation should stay longer than other customers, but that effect was not found in this study. Customers sitting at anchored tables did not have a significantly different dining duration than those seated at unanchored tables (anchored $=46.8$ minutes, unanchored $=46.5$ minutes). Customers in larger parties stayed longer $(r=.14)$, while table size was not signilicantly related to meal duration $(r=.05)$.

Type of anchor. As with SPM, banquettes were significantly different from other tables in terms of duration. Customers seated at banquettes had a significantly longer dining duration than customers seated at other table types 
Exhibit 8:

Meal Duration: Regression Results

\begin{tabular}{|c|c|c|c|}
\hline \multicolumn{2}{|c|}{ Anchored Tables } & \multicolumn{2}{|c|}{ Table Configuration } \\
\hline Variable & Coefficient & Variable & Coefficient \\
\hline Constant & $39.21 *$ & Constant & $40.58^{*}$ \\
\hline Anchored? & 1.56 & Diagonal & -1.58 \\
\hline Party size & $2.11^{*}$ & Side by side & -2.6 \\
\hline Table size & $1.55^{*}$ & Party size & $2.15^{*}$ \\
\hline \multirow[t]{2}{*}{$R$-squared } & $1.90 \%$ & Table size & 2.73 \\
\hline & & $R$-squared & $1.90 \%$ \\
\hline \multicolumn{2}{|c|}{ Type of Anchor } & \multicolumn{2}{|c|}{ Table Quality } \\
\hline Variable & Coefficient & Variable & Coefficient \\
\hline Constant & $39.47^{*}$ & Constant & $41.95^{*}$ \\
\hline Banquette & $5.55^{*}$ & Bad & $-4.47^{*}$ \\
\hline Booth & 1.72 & Party size & $2.04^{*}$ \\
\hline Half-wall & 1.55 & Table size & -0.03 \\
\hline Interior window & -0.3 & $R$-squared & $2.30 \%$ \\
\hline Window & 1.62 & & \\
\hline Party size & $2.03^{*}$ & & \\
\hline Table size & 1.52 & & \\
\hline$R$-squared & $2.00 \%$ & & \\
\hline
\end{tabular}

*Significant at the .05 level.

(banquette $=51.1$ minutes, all tables $=$ 46.7 minutes).

Table configuration and quality. Table configuration did not have a significant impact on dining duration (diagonal = 47.4 minutes, side by side $=47.4$ minutes) . However, customers seated at bad tables stayed a significantly shorter time than those seated at good tables (bad $=41.7$ minutes, good $=47.4$ minutes).

\section{Manipulatiog Privacy}

For the most part, we observed little difference in spending and duration behavior across table types with two notable exceptions: guests had significantly longer duration and thus lower SPM at banquette seats and significantly shorter duration and thus higher SPM at bad tables. In addition, booth seating generated a higher average check, but it did not generate a significantly higher SPM than other table types because of a longer than average duration.

As might be predicted from the literature, tables that offered more potential for privacy regulation generally resulted in a higher average check and a longer than average duration. Tables that were more exposed, such as those along interior windows facing the patio, had a lower average check and a shorter average duration. This was not surprising because diners being observed at close range by other patrons (sitting on the patio) may be experiencing a fishbowl effect that is likely to increase discomfort and discourage a leisurely 
meal. This finding is in keeping with the demonstrated relationship between a pleasant shopping environment and higher spending." It also lends partial support to the approach-avoidance theories of Melurabian and Russell, which hold that an attractive environment increases approach behavior. "However, their model suggests that an attractive setting would not only contribute to increased performance (which might be operationalized as higher spending), but it also implies that patrons would wish to stay longer in that environment, an attribute that is not always desirable in a restaurant setting.

However, some of our findings surprised us. We expected that the lack of privacy at banquette seating would lead to shorter durations, but in fact, duration at banquettes was the longest of all table types and, combined with lower spending. resulted in the lowest SPM we observed We could not determine an underlying cause of this longer duration from our data, and we suggest that additional studics be performed in different restaurant types to further analyze this observed relationship.

The finding that bancjuette seating contributes to a longer duration and lower average check has particular importance for restaurant designers, as this style of seating is frequently adopted as being both an efficient use of space and a highly llexible seating arrangement that can bo modified quickly to accommodate a wide range of party sizes. If bancjuette seating has a negative influence on SPM (and causes low-spending guests to linger), this kind of seating might nol be as desirable as is customarily thought.

We were also surprised to see how little difference there was between anchored and unanchored tables and between different table configurations across all mea- sures. While studies of interaction suggest that anchored tables and diagonal seating are preferred, we did not see any noticeable dillerence in spending or duration for these types of tables.

The shorter duration at bad tables41.7 minutes as opposed to the mean durattion of 47.4 minutes for all tables-might be explained by the discomfort and lack of privacy associated with an exposed location next to the kitchen or other service atcas, but spending at these poorly placed tables was no different than for other locations in the restaurant. Patrons maly prefer to sit elsewhere, but our observations suggest that they may spend just as much on their meal al a poorly placed table. Again, this finding scems counter to the theories of approach-avoidance behavior and suggests that further reseatch in a varicty of restaurant settings is necessary. However. these data were collected during peak demand periods, which may have affected patrons' behavior: When tathles are in high demand, even a "bad" lable may be desirable and generate high spending.

In summary, these findings suggest that seats that offer greater privacy are preferted by customers. Whether they should bo prefered by restaurateurs is another matter. To maximize revenue, we suggest that a better measure than averatge check or duration is SPM by table type. By this slandard, our only signilicant findings were that banquette seats generated a lower SPM that other lables and badly localed tables generated a higher than expected SPM. Larger parties also exhibiled a lower than average SPM through a combination of increased duration and a lower average check per person.

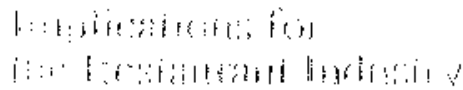

A demonstrated relationship between table characteristics and patrons" behavior 
can serve both restaurant designers and managers in their efforts to create more profitable operations. The finding that banquette seating resulted in a longer duration and a significantly lower average check per person than other types of seating at this casual restaurant suggests that restaurant planners may wish to reexamine the use of this type of seating in some applications. While banquette seating is space efficient and gives the operator flexibility in accommodating parties of various sizes, these benefits must be weighed against the potential for maximizing revenue through an increased SPM suggested by other table types. Of course, more research needs to be done before we suggest replacing all banquette seating with booths, but exploring alternative seating schemes might be warranted given our initial findings.

What most designers and operators consider to be a bad table did not in this case appear to affect patrons" spending at those tables and in fact seemed to increase the potential for revenue generation by reducing the length of stay. This is not to suggest that designers should purposely create poor table locations, but it does indicate to the restaurant planner that extreme and sometimes expensive efforts to eliminate undesirable seats in a dining room layout may not be justified, depending on the type of operation.

For restaurant managers, our findings suggest opportunities to fine-tune operations and possibly increase revenues. Operators that adopt revenue management strategies that are intended to decrease duration during peak periods might manipulate their restaurant's seating chart to maximize short-duration table types or seat large parties at freestanding tables rather than at banquettes. Along that line, server stations may be better balanced across different types of tables--booths, banquettes, and freestanding-to ensure that servers have a mix of parties with different rates of SPM. Additionally, since a manager can expect different durations at different table types, that manager could schedule servers for certain tables based on the servers' style or skill.

\section{Complusion}

While not all table characteristics appeared to affect customers' behavior in this study, we found that booths generated the highest SPM of all table types, banquette seating generated the lowest SPM, and what most people might term a bad table still generated a reasonable rate of SPM during busy times. These findings are based solely on a single restaurant, but they suggest that there may be interesting relationships between a restaurant's environment and its customers' behavior that merit more investigation as well as consideration by restaurant planners and managers as they create new and more effective amenities.

\section{Endnotes}

1. S. E. Kimes, "Restaurant Revenuc Management: Implementation at Chevys Arrowhead," Cornell Hotel and Restatrant Adminisfration Quarterly' 44, no. 4 (2004): 52-67.

2. S. E. Kimes, R. B. Chase, S. Choi, P. Y. Lee, and E. N. Ngonzi, "Restaurant Revenue Management: Applying Yield Management to the Restatrant Industry," Comell Hotet and Restanatm Administration Quaterly 39, no. 3 (1998): 32-39).

3. H. Proshansky, W. Ittelson, and L. Rivlin. "Freedom of Choice and Behavior in a Physical Setting: Some Basic Assumptons," in Envirommental Poychology: Mat and His Phrsical Setting (New York: Holt, Rinehart and Winston, 1970).

4. G. W. Guyot, G. R. Byrd, and R. Caudle. "Classroom Seating: An Expression of Situational Territoriality in Humans," Simall Group Behavior II, no. I (1980): 120.28: and I. Altman, The Enviroment and Sociat 
Behavior (Pacific Grove, CA: Brooks/Cole, 1975).

5. J. Archea, "The Place of Architectural Factors in Behavioral Theories of Privacy," Journal of Social Issues 33, no. 3 (1977): 116-37; and J. Cheyne and M. Efran, "Eflect of Spatial and Interpersonal Variables on the Invasion of Group Controlled Territories," Sociometry 35, no. 3 (1972): 477-89.

6. A. Mehrabian and S. G. Diamond, "Scating Arrangement and Conversation," Sociometry 34, no. 2 (1971): 281-89; and R. Sommer, Personal Space: The Behavioral Basis of Design (Englewood Cliffs. NJ: Prentice Hall, 1969).

7. M. L. Patterson, C. E. Kelly, B. A Kondracki, and L. J. Wulf, "Effects of Seating Arrangement on Small-Group Behavior," Social Psychology Quarterly 42, no. 20 (1979): 180-85

8. For two of many examples of studies in this area, see D. M. Pedersen, "Personality and Classroom Seating," Perceptual and Motor Skills 78, no. 3, pt. 2 (1994): 1355-60; and C. I. Brooks and J. L. Rebeta, "College Classroom Ecology: The Relation of Sex of Student to Classroom Performance and Seating Preference," Environment and Behavior 23, no. 3 (1991): 305-13.

9. P. Collett and P. Marsh, "Seat Choice in an Airport Lounge," Man-Envirorment Systems 10, no. 2 (1980): 83-106; and A. N. Kenner and G. Katsimaglis, "Gender Differences in Proxemics: Taxi-Seat Choice," Psychological Reports 72, no. 2 (1993): 625-26.

10. A. Mehrabian and J. A. Russell. An Approach to Envirommental Psychology (Cambridge, MA: MIT Press, 1974).

11. R. J. Donovan, J. R. Rossiter, G. Marcoolyn, and A. Nesdale, "Store Atmosphere and Purchasing Behavior," Journal of Retailing. 70, no. 3 (1994): 284-94.

12. R. Sommer and J. Steele, "Social Effects on Duration in Restaurants," Appetite 29 (1997): 25-30

13. A. C. North, A. Shilcock, and D. J. Hargreaves, "The Effect of Musical Style on Restaurant Customers' Spending," Environment and Behavior 35, no. 5 (2003): 712-18.

14. S. K. A. Robson, "Turning the Tables: The Psychology of Design for High-Volume Restaurants," Cornell Hotel and Restaurant Administration Quarterly 40, no. 3 (1999): 56-63.
15. R. E. Milliman, "The Influence of Background Music on the Behavior of Restaurant Patrons," Journal of Consumer Research 13, no, 2 (1986): 286-89

16. S. K. A. Robson, "A Review of Psychological and Cultural Effects on Seating Behavior and Their Application to Foodservice Settings," Journal of Foodservice Business Research 5, no. 2 (2002): 89-107; and S. K. A. Robson, "Restaurant Seating Pref. erences in Dilferent Dining Scenarios" (working paper, School of Hotel Administration, Cornell University, Ithaca, NY, 2004).

17. S. E. Kimes and G. M. Thompson, "A Comparison of Techniques for Identifying Optimal and Near-Optimal Restaurant Table Mixes" (working paper 09-04-(12, School of Hotel Administration, Cornell University, Ithaca, NY, 2002).

18. G. M. Thompson, "Optimizing RestaurantTable Configurations: Specifying Combinable Tables," Cornell Hotel and Restauramt Administration Quarterly 44, no. I (2003): $53-60$

19. Donovan et al., "Store Atmosphere and Purchasing Behavior."

20. For a full discussion of this restaurant, please see Kimes, "Restaurant Revenue Management," 52-57.

21. Donovan et al., "Store Atmosphere and Purchasing Behavior:"

22. Mehrabian and Russell, An Approach to Environmental Psychology.

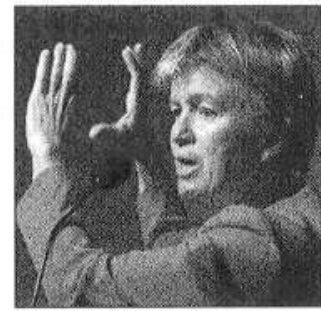

Sheryl E. Kimes, $\mathrm{Ph} . \mathrm{D}$., is a professor at the Cornell University School of Hotel Administration (sek6@cornell.edu).

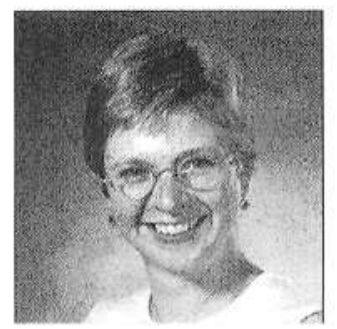

Stephani K. A. Robson, M.S., is a lecturer at the Cornell University School of Hotel Administration (skr4@cornell.edu). 